\title{
Isolated Testicular Tuberculosis in a 9-Year-Old Boy: An Incidental Finding
}

\author{
Hassan Shehu ${ }^{1,}$, Maryam Shehu ${ }^{2}$, Oseni Momodu ${ }^{1}$, Sunday Gargadi ${ }^{1}$ \\ ${ }^{1}$ Department of Surgery, Bingham University Teaching Hospital, Jos, Nigeria \\ ${ }^{2}$ Department of Paediatrics, Bingham University Teaching Hospital, Jos, Nigeria
}

Email address:

hassy752001@gmail.com (H. Shehu)

${ }^{*}$ Corresponding author

To cite this article:

Hassan Shehu, Maryam Shehu, Oseni Momodu, Sunday Gargadi. Isolated Testicular Tuberculosis in a 9-Year-Old Boy: An Incidental Finding. Journal of Surgery. Vol. 7, No. 4, 2019, pp. 101-103. doi: 10.11648/j.js.20190704.13

Received: May 17, 2019; Accepted: July 1, 2019; Published: July 12, 2019

\begin{abstract}
Isolated testicular Tuberculosis (TB) is a rare clinical condition. A 9-year old boy presented to the paediatric surgical clinic with a 3-month history of a painless mass in the right testis and 1-month history of low- grade continuous fever. The boy had normal anthropometry, no abnormal respiratory signs, there was a right hemiscrotal swelling with a solid hard, non- tender mass felt on the upper pole of the right testis. The chest radiograph was normal, histopatholgic results of the mass showed tuberculotic granuloma with caseous necrosis, FBC revealed WBC of $9.7 \times 10^{3} / \mathrm{MM}^{3}$, HCT-33\% Platelets$357 \times 10^{3} / \mathrm{MM}^{3}$, Neutrophil-24, Lymphocyte-34, Eosinophils-1O, Monocyte-30, Basophils-2, ESR-26mm $/ \mathrm{hr}$, Mantoux-0 $\mathrm{mm}^{2}$, Cytology smear revealed a mixed inflammation consisting mainly neutrophils and plasma cells with an eosinophilic background. Hydrocele fluid aspirate for $\mathrm{M} / \mathrm{C} / \mathrm{S}$ showed no significant bacterial growth. To date, no clinical method has been defined for the definitive diagnosis of such cases and the definitive diagnosis is only achieved by surgical exploration and histopathological examination. Testicular tuberculosis (TB), a rare form of (EP-TB), may present with diagnostic challenge.
\end{abstract}

Keywords: Cytology, Genitourinary Tuberculosis, Testis, Boy, Jos

\section{Introduction}

Majority of people think that tuberculosis affects only the lungs, but in reality, it can affect almost every part of the body [1]. However, the commonest part of the body it affects is the lungs and extra- pulmonary TB accounts for about $10-15 \%[2,3]$. While genitourinary tuberculosis (GUTB) accounts for up to $30 \%$ of extrapulmonary TB, epididymal involvement accounts for only about $20 \%$ of GUTB In Extra-pulmonary TB [4]. Genital TB can affect the whole male genital organs; epididymis, testis, prostate, seminal vesicle, vas deferens, scrotal skin, bulbourethral glands and penis [5]. Genital TB is uncommon, and testicular $\mathrm{TB}$ is further rare, comprising only $3 \%$ of genital TB [3]. When there is genital TB, the genital organ most affected is the epididymis. Dissemination is thought to occur either by downward extension of a renal focus or hematogenously [6]. Almost all the testicular TB clinically mimics other testicular lesions, such as testicular tumor, infarction, or even testicular torsion. Middle-aged males, especially of 20-40 years of age are most commonly affected, and presented with painful or painless scrotal swelling with or without discharging sinus [3]. This makes the diagnosis of testicular and epididymal TB very challenging, especially if it is isolated [6].

This is a case report of epididymal and testicular TB in a 9-year-old boy where the diagnosis was made after the child had an operation for right non-communicating hydrocele and a mass was found in the epididymis and on the upper pole of the right testis, which was biopsied and specimen was sent for histology which revealed features of granulomatous reaction suggesting TB.

The aim of this article is to raise the awareness on the possible presentation of testicular TB in children with no other symptoms other than a scrotal swelling, so as to prevent delayed diagnosis and prevent complications associated with delayed treatment and missed diagnosis. 


\section{Case Report}

A 9-year-old boy from Jos presented to the paediatric surgical outpatient department with a history of a painless right scrotal swelling of 3 months and fever of one-month duration respectively.

A swelling was noticed in the right scrotum, which was initially the size of a peanut but however progressively increased to triple its size within 3 months, the swelling became hard however remained painless. This is the first episode of such swellings in patient's life, the swelling never regressed, no history of swelling in the left scrotum or any other part of the body, no preceding history of trauma.

Fever started about a month after the above symptoms, low-grade and continuous. Additional history gotten after the diagnosis included a history of excessive night sweats and weight loss. There is a positive history of a chronically coughing pupil in his class who was his best friend. There were no respiratory symptoms, patient is fully vaccinated for age, other systemic review was essentially normal.

On presentation, he was afebrile with a temperature of $\left(36^{\circ} \mathrm{C}\right)$, not pale, anicteric, acyanosed, no significant peripheral lymphadenopathy. Anthropometry was within normal limits. Urogenital system revealed right hemiscrotal swelling, measuring about $4 \mathrm{~cm}$ by $5 \mathrm{~cm}$, no color change, no differential warmth, non-tender, cough impulse and palpable cough impulse were negative. A firm mass was felt on the superior aspect of the testis and attached to the right spermatic cord. Left testis was smooth and soft measuring about 3 by $2 \mathrm{~cm}$, respiratory rate of $22 \mathrm{c} / \mathrm{m}$, and oxygen saturation of $99 \%$ on room air, vesicular breath sounds, he had a pulse rate of $83 \mathrm{~b} / \mathrm{m}$ blood pressure $90 / 70 \mathrm{mmhg}$, heart sounds S1 and S2. Abdominal examination - No palpable organomegaly.

FBC revealed a total leukocyte count of $9.7 \times 10^{3} / \mathrm{MM}^{3}$, HCT $33 \%$, Platelets-357 $\times 10^{3} / \mathrm{MM}^{3}$, Neutrophil-24, Lymphocyte-34, Eosinophils-1O, Monocyte-30, Basophil-2. ESR- $26 \mathrm{~mm} / \mathrm{hr}$. Chest $\mathrm{x}$-ray was normal and mantoux test was $0 \mathrm{~mm}^{2}$. Cytology smear of the fluid aspirate from the hydrocele revealed a mixed inflammation consisting of mainly neutrophils and plasma cells with an eosinophilic background. Fluid aspirate for $\mathrm{M} / \mathrm{C} / \mathrm{S}$ showed no significant bacterial growth. Histopathological analysis of the mass taken from the testis and epididymis showed several foci of granulomas which contains lymphocytes, epitheliod cells, histiocytes, fibroblasts and multinucleated giant cells. Central areas of necrosis are also observed. Diagnosis was that of a tuberculous mass. tuberculous lymphadenitis.

The intra-operation findings were that of hydrocele and a hard mass extending from the right epididymis to the right testis, the hydrocele sac was laid opened and biopsy of the mass was taken for histology.

Patient was reviewed at the TB clinic following the results of the biopsy, where he was commenced on Anti-tb drugs consisting of HRZE, for 6 months, he is on follow-up and doing well.

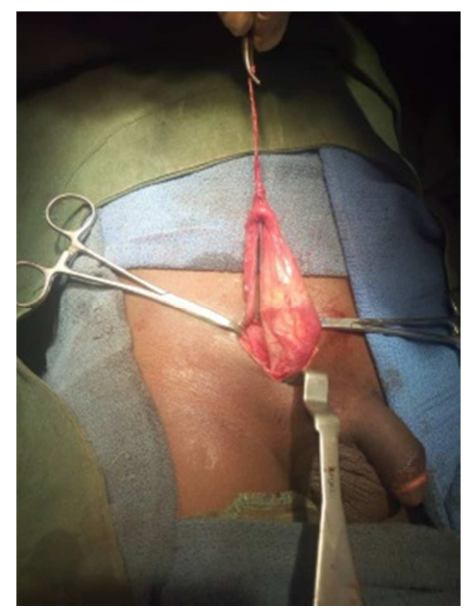

Figure 1. Irregular, thickened slightly enlarge right epididymis.

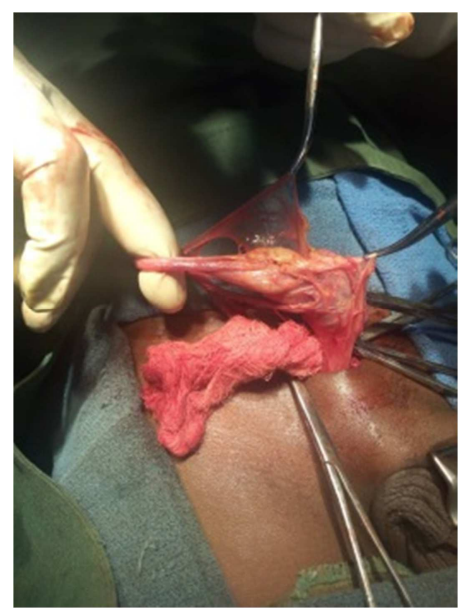

Intra operative pictures.

Figure 2. Hydrocele and mild enlargement of right testes.

\section{Discussion}

Genitourinary TB is the second most common site of involvement among extra-pulmonary $\mathrm{TB}$ after lymph node involvement. [7]. The most common site of genital TB is the epididymis, followed by the seminal vesicles, prostate, testis, and the vas deferens [8]. Genital TB occurs usually, through hematogenic spread to the epididymis and prostate or through the urinary system to the prostate and canalicular spread to the seminal vesicles, deferent ducts, and epididymis [9]. Testicular involvement is mostly due to local spread from the epididymis and rarely by haematogenous spread [10]. Cabral et al said that higher frequency of isolated lesions in children favoured the possibility of haematological spread of infection [11].

However, genitourinary tuberculosis presents a diagnostic challenge [6] especially when it is an isolated epididymal or testicular Tuberculosis [9]. Frequently, patients present with only scrotal/testicular mass with or without pain/tenderness and no any other urinary or systemic symptom, the most common presentation is said to be painless scrotal mass [9, $12,13]$. The symptoms are usually insidious and progressive, and can easily be confused with other infections in the epididymis/testis, cysts and tumors [9, 12]. 
The index patient was a boy that presented with right irreducible non- progressive painless hemiscrotal swellings, that trans illuminates, with an abnormally large hard testes felt within the size of the swelling, with no systemic symptoms. The diagnosis was secondary hydrocele to rule out a testicular tumour, this presentation supports other literature that states that $\mathrm{TB}$ of the genitals could presents as an isolated TB, with the epididymis being the commonest, without urinary symptoms, as a painless mass or hydrocele $[3,5,10,11,14]$. However it is of interest to note that all these Literature reported cases in men, except for Cabral who reported two cases in children [11].

Because of the difficulty in diagnosing Isolated genital TB, it leads to a lot of missed diagnosis like testicular tumour, bacterial epididymo-orchitis as well as testicular torsion and sarcoid and testicular cancer. The diagnosis is usually done after invasive procedure which in most cases included total to partial orchidectomy as they were mostly suspected to have testicular tumours [9-10, 14-16]. Non- invasive investigations like USS, CXR, Mantoux, ESR, MRI and even semi invasive ones like FNAC are not usually diagnostic and therefore can easily lead to a missed diagnosis [9, 17-18].

The treatment for testicular or epididymal TB is usually the giving of Anti tuberculosis drugs without the need for orchidectomy or removal of the mass $[14,19]$, however, because of its usually diagnosis retrospectively, this has not been the case.

\section{Conclusion}

A high index of suspicion is needed to diagnose genital TB especially in children so as to avoid unnecessary procedures, ochidectomy and indiscriminate use of antibiotics. Although, for a definitive diagnosis of isolated cases of genital TB, there may be need for a biopsy of the mass.

\section{References}

[1] Shugaba AI, Rabiu AM, Uzokwe C, Matthew RM. Tuberculosis of the testis: a case report. Clin Med Insights Case Rep [Internet]. SAGE Publications; 2012 [cited 2018 Sep 28]; 5: 169-72. Available from: http://www.ncbi.nlm.nih.gov/pubmed/23300353.

[2] Article O, Singh JP, Priyadarshi V, Kundu AK, Bera MK, Pal DK. Table 1: Characteristics GUTB patients in study Table 2: Site of involvement in IVP in GUTB patients. Indian J Tuberc. 2012; 020 (09903605262): 15-22.

[3] Das A, Batabyal S, Bhattacharjee S, Sengupta A. A rare case of isolated testicular tuberculosis and review of literature. J Fam Med Prim care [Internet]. Wolters Kluwer -- Medknow Publications; 2016 [cited 2018 Sep 29]; 5 (2): 468-70. Available http://www.ncbi.nlm.nih.gov/pubmed/27843865.

[4] Papadopoulos A, Bartziokas K, Morphopoulos G, Anastasiadis A, Makris D. A rare case of isolated tuberculous epididymitis in a young man presenting with a swollen testicle Four months: $1-3$.
[5] Vuilleumier N. Head-to-Head Comparison of Auto-Antibodies for Cardiovascular Outcome Prediction after Myocardial Infarction: a Prospective Study. J Clin Exp Cardiolog [Internet]. 2011; 02 (11): 9-11. Available from: https://www.omicsonline.org/head-to-head-comparison-ofauto-antibodies-for-cardiovascular-outcome-prediction-aftermyocardial-infarction-a-prospective-study-21559880.1000169.php?aid=3246.

[6] Report C. Epididymal tuberculosis: Case report. 2008; 2 (June): $38-41$.

[7] Sharma SK, Mohan A. Extra-pulmonary tuberculosis. Indian J Med Res. 2004; 120: 316-53.

[8] Lamichaney R, Das D, Sherpa M. Koch's Disease Presenting as an Isolated Testicular Mass- An Unusual Occurance. J Clin Diagn Res [Internet]. JCDR Research \& Publications Private Limited; 2014 Sep [cited 2018 Sep 28]; 8 (9): FD13-5. Available

from: http://www.ncbi.nlm.nih.gov/pubmed/25386448.

[9] Medical C. Isolated tuberculous epididymitis: A review of forty cases. 2005; 51 (2): 109-11.

[10] Wise GJ, Shteynshlyuger A. An update on lower urinary tract tuberculosis. Curr Urol Rep. 2008; 9: 305-13.

[11] Cabral DA et al. Tuberculous epididymitis as a cause of testicular pseudomalignancy in two young children. pediatr infect Dis 1985; 4: 59-62.

[12] Gorse GJ, Belshe RB, Male genital tuberculosis: a review of the literature with instructive case reports. Rev Infect Dis. 1985; 7 (4): 511-24.

[13] Badmos KB, Tuberculous epididymo-orchitis mimicking a testicular tumour: a case report. African Health Sciences 2012; 12 (3): 396 - 398 http://dx.doi.org/10.4314/ahs.v12i3.24.

[14] Viswaroop BS, Kekre N, Gopalakrishnan G. Isolated tuberculous epididymitis: a review of forty cases. J Postgrad Med [Internet]. [cited 2018 Sep 29]; 51 (2): 109-11, discussion $111 . \quad$ Available from: http://www.ncbi.nlm.nih.gov/pubmed/16006701.

[15] Viveiros F, Tente D, Espiridião P, Carvalho A, Duarte R. [Testicular tuberculosis: case report]. Rev Port Pneumol [Internet]. [cited 2018 Sep 29]; 15 (6): 1193-7. Available from: http://www.ncbi.nlm.nih.gov/pubmed/19859635.

[16] Taken K, Ekin S, Canbey O, Günes M, Bulut G. SM Gr up SM Journal of Isolated Testicular Tuberculosis Mimicking Testicular Cancer: A Case Report and Literature Review. 2015; 1 (1): 1-3.

[17] Young S C, Kwan J J, Chil H K, Heung J P; Tuberculosis of testis and prostate that mimicked testicular cancer in young male soccer player J Exerc Rehabil ; 2013; 9 (3): 389-393. Available from https://doi.org/10.12965/jer.130046.

[18] Muttarak M, Peh WC et al. Tuberculous epididymitis and epididymo-orchitis: sonographic appearances. AJR Am J Roentgenol 2001; 176: 1459-1466.

[19] Cek M, Lenk S, Naber KG, Bishop MC, Johansen TEB, Botto $\mathrm{H}$, et al. EAU Guidelines for the Management of Genitourinary Tuberculosis. Eur Urol [Internet]. 2005 Sep [cited 2018 Sep 29]; 48 (3): 353-62. Available from: http://www.ncbi.nlm.nih.gov/pubmed/15982799. 